\title{
From the Self to the 0ther and Back Again: Intersubjectivity as a Perpetual Motion Around the Self
}

\section{Introduction}

The concept of intersubjectivity can be understood and operationalized in at least two different ways. According to what we may call the principle of procedural transparency, intersubjectivity is associated with replicability of experimental results. This principle dates back to Popper's philosophy of science (2002) and is well entrenched in the social sciences. The basic idea is that a given theoretical concept is valid if the procedure that produced it is laid out sufficiently clearly for any competent agent to be able to follow it in the hopes of achieving a similar result. This conception establishes a close, almost one-to-one link between intersubjectivity (qua intersubjective criticizability) and objectivity, construed as a justified conviction that a given method allows to accurately account for relationships between different phenomena. A related, judicial conception of objectivity as impartiality has it that a theory or judgment is objective if and only if (iff) it covers all the relevant angles of the object or phenomenon in question, ensuring that the latter is not ephemeral. In the methodology of the sciences, this idea is expressed as construct validity.

In the aftermath of William Dray's critique of Hempel's law covering model as applied to social phenomena (Dray, 1957; for a whole discussion, see Apel, 1984), an alternative view was developed in the philosophy of the human sciences. Based on the assumption that in the social sciences, a researcher is also a participant, it was proposed that intersubjectivity is a matter of understanding, as opposed to explanation, and rests on sharing of a lifeworld and associated practices (Winch, 2003; Von Wright, 1971), empathy (Lipps, 1979; Kögler \& Stueber, 2000; Gallese, 2003, 2005), or some form of direct social cognition (Scheler, 1954; Gallagher, 2008; Gallagher \& Zahavi, 2008). Theorists of intersubjective understanding are much less concerned with the problematic of reference as compared with those operating from the principle of replicability (Apel, 1998). They target meanings rather than facts.

My aim in this paper is to bring some elements of Gestalt theory - and more specifically, Rudolf Arnheim's (1988) adapted model of field dynamics - to bear

Polish Academy of Sciences, Warsaw, Poland.

O Open Access. ๑ 2020 Anna Michalska, published by Sciendo. (c) BY-NC-ND This work is licensed under the Creative Commons Attribution NonCommercial-NoDerivatives 4.0 License. 
on the problematic of intersubjectivity and show that the three conceptions of intersubjectivity are interconnected and that all three are necessary to fully account for the phenomenon. The proposed model entails that intersubjectivity is a dynamic phenomenon, best described as a product of two vectors: a vector describing a movement across the circumference combined with a vector describing the movement from the center to the circumference. While the first vector corresponds to impartiality, the second represents the tension between cognitive distancing and direct experience. Overall, it is argued that intersubjectivity cannot be divorced from either subjectivity or objectivity and that it amounts to skillful navigation within and across frames of reference.

\section{Center and Circumference}

Without further ado, I will proceed to lay down the model of field dynamics as applied to interaction and cognition. The model in question is based on centerperiphery dynamics, but in contrast to other models utilizing the same schemaespecially Gardenförs's model of conceptual spaces (2004) and Quine's model of field of forces (1953) - it takes gestalts, as opposed to concepts, to be the main currency of human transactions with the world. In Gardenförs's conceptualization, for instance, periphery represents objects that fall furthest from a given conceptual prototype and hence are most contaminated by other categorical frameworks, which is a way to say that boundaries between concepts are fuzzy. By contrast, in my account, which is inspired mainly by Rudolf Arnheim's (1988) conception of field dynamics, the center represents a place or a moment at which our contact with an object is most direct. Accordingly, circumference signifies a growing conceptual-linguistic mediation. Simply put, the model delineated below is not concerned with conceptual spaces in abstracto, but rather, it conceptualizes our relationships with objects at all levels.

Figure 1 shows a transition from the primordial unity to first-level differentiation (split, dyad), where the resultant tension eventually gives rise to multiplicity. We can come across this schema in many esoteric writings, where it is used to depict the process of successive emanation of the manifest universe, characterized by an infinite variety of possible forms. ${ }^{1}$ What is interesting, however, is that the model is also applicable to mundane phenomena, such as the progressive emergence of a living organism from a single cell (zygote) in the process of successive subdivisions, as well as child development. Concerning the latter, the fundamental unity represents, roughly, a state of union with the mother, whereas the dyad relates to the first experience of separation from the "source", when the

\footnotetext{
1 See, e.g., Plato's Timaeus, Plotinus's Enneads, The Works of Dionysius the Areopagite, the classic Kabbalistic treaty, Zohar. The schema is also present in Indian cosmogony.
} 
child realizes that not all its needs and demands can be automatically satisfied (Klein, 1986). The idea of otherness is being formed as a result, and a learning process begins.
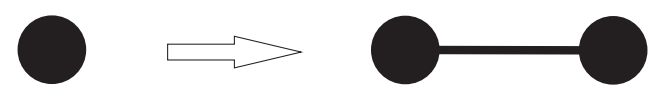

Fig. 1. From ideal unity to dyad.

The outcome of the process is schematically presented in Figure 2, which shows a circle with a center from which "rays" are coming out in all directions and a circumference that encloses it. Rays represent the infinite number of dimensions of any given object. In other words, what is represented by the circle around the center is that each object or phenomenon is multifaceted and that there is a natural drive in every living organism to move beyond what is currently given, the exploration being circumscribed by the current level of psychosomatic organization. The whole figure can hence be taken to portray a frame of reference within the bounds of which all interactions take place. It can also be applied to particular pursuits, which are based on the same organizational structure, or, put another way, are a result of recursive procedures as applied to the general frame of reference.

The idea behind this imagery is expressed in theses 2.014-2.0141 of Tractatus, which state that "Objects contain the possibility of all situations. The possibility of its occurring in states of affairs is the form of an object." (Wittgenstein, 1922) To this, we must add, however, that a frame of reference represents both the object and the subject. The object is that which is indivisible and contains the possibility of all situations in which it can be encountered, and thereby all the angles from which it can be approached. But we can also turn this assertion around and say that every subject represents the capacity of interaction with an infinite number of objects and their dimensions, which amounts to internal complexity or selfdifferentiation. In the presented schema, both statements are true.

A more fundamental caveat to the Wittgensteinian idea of a one-to-one correspondence between the content and the means of expression (the so-called

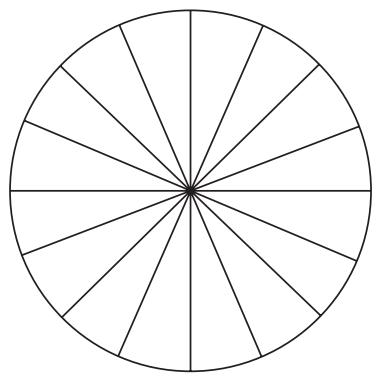

Fig. 2. Multidimensionality of the object - the general frame of reference. 
Logical Connection Argument: see Landesmann, 1965; Apel, 1998, 1984), is that Figure 2 represents a God-like perspective on a subject matter. Empirical reality, represented by particular points and vectors in the spaciotemporal continuum, can never live up to a perfect integration of all relevant perspectives. In Neoplatonist metaphysics, for instance, God is conceptualized as a paradoxical state in which the center is fully aligned with the circumference; infinite extension and infinite concentration or density are two facets of the same thing, the totality. Being as we are finite creatures, however, we are always shifted with respect to any center, slightly of out of focus, which sets the dynamic of the real versus ideal dimension (cf. Apel, 1998). I will return to this in just a moment. In other words, Figure 2 represents the transcendental unity of subject-object, which, as far as every day interactions are concerned, is always to some degree counterfactual.

The dynamic of every problem situation is determined by two counteracting forces operating simultaneously: centripetal and centrifugal forces. In order to get a sense of this, let us imagine two spiraling movements, one from the center toward a certain point at the circumference, and the other in the opposite direction. While the former represents the center's power of integration and cohesion, the latter describes a progressive expansion of the frame of reference. In other words, the movement from the periphery to the center represents a destructive force, and hence the fact that the closer we get to the heart of a matter, the more useless and inadequate the forms (representations) become. The centripetal force, in turn, is a constructive (or anabolic: Arnheim, 1971) agent: it is responsible for the creation of form (representation). As mentioned above, were it not for the centrifugal force, the individual would be crushed by the gravitational pull of the center (Neumann, 1963). In other words, the center is an equivalent of the thing-initself. It is unapproachable, unfathomable, and ineffable not because it is located somewhere "out there", but to the contrary, because it lies in the very core of the frame of reference and is the source of that which affords itself. Put another way, every center is the Wittgenstein's "limit", a pure driving force that is impossible to grasp and control (cf. Lyotard, 2011). The only thing we can, to some degree, control is the distance from it and the movement around it.

The risks associated with any imbalance between centripetal (catabolic) and centrifugal (anabolic) forces can be illustrated by two clinical examples. In severe autism, one tries as much as one can to steer clear of the center. In this case, one experiences subject-object division in its purest form: the division is rigidly upheld because all exteriorizations are perceived as unequivocally threatening. There is no exploration because there is no multitude of perspectives normally available to the agent; the world is reduced to a single dimension. As Michael Fordham points out (1976), autism is a failure at the level of symbolization: the autistic child has difficulties treating what he/she perceives as aspects of a whole to 
explore and tends to take whatever presents itself as the object per se, in a pars-prototo kind of way. It is not that, let me emphasize, the autistic child does not have a sense of reality; conversely, it seems like the reality is simply too overwhelming for them to allow it to unfold spontaneously. For a severely autistic person, the object is a source of pure resistance to overcome, which produces rigid defenses. That is to say that meaning (that which is "internal") and reference (that which is "external") are dissociated here, making it impossible for the person to explore the multiplicity of appearances reflective of their potential for differentiation.

On the other extreme, we get psychosis, which is typically associated with an intense exploration. On the face of it, there is a lot of vigorous movement across many dimensions involved in psychosis. The problem in this case is that the explorer loses connection with the center. When in a state of psychosis, a person traverses different fields, creating ever more elaborate analogies, but this with no bearing on any particular object or topic. Underlying this seeming freedom of thought and expression is an obsession with a specific theme, whereby aspects and features become dissociated from objects that actually carry them. This can also be seen as deficiency on the level of symbolization but, this time, stemming from the inability to bring different facets of a gestalt together and allow them to converge upon a center.

Simply put, the center is the position where we are most directly affected by an object, to the point of annihilation of form. A direct contact with an object is associated with the risk of being consumed, devoured, overpowered, and stripped of identity, ego, or even physical existence. On the other hand, the anabolic force, unless counterbalanced, either leads to solidification to the point of objectification, with associated tunnel vision and bias, or causes disorganization. These two extreme distortions of the frames of reference testify to the fact that in optimal conditions, objects are perceived as neither strictly external nor internal. The experience of objects as external is due to the fact that all that we experience is always-already a deintegrate (split-off) and delineates possible explorative trajectories and strategies (Fordham, 1981). At the same time, all things being equal, objects are also internal in that they are conceived of as belonging to a certain frame of reference that we share with these objects and are able to navigate. A frame of reference (or field) is what binds the subject and the object together in a kind of a dance. In other words, every field represents both qualities of the object of interaction and our own capacities to deal with it, as well as possible goals and values.

Compare what has been said so far with Gardenförs's model of conceptual space, according to which every concept is a "convex" area (region) in a conceptual space. A concept is a gravitational center in a given space, while centers are places in which prototypes reside. Every object can hence be categorized based on its 
distance from a center: the closer the object is located with respect to a certain center, the better it epitomizes the associated concept-prototype. Apart from the fact that our model deals with gestalts rather than concepts - the concept being a component part of the gestalt rather than a unit of meaning in its own right (see Figure 5) - what is critical to understand is that every, even the most basic, prototype or exemplar is already a deintegrate of the center, in need of elaboration, and ultimately, reintegration. In other words, the strict center is a pure force - a black hole, as it were - not a prototype. This is yet another way to say that the logical connection argument only describes a mystical union, which is unachievable in ordinary circumstances (if at all). That prototypes themselves are split-offs from pertinent centers means that we need to play with perspective to remain in tune with the world (and ourselves). The corollary to this is that the same intentional object can be expressed, manifested, and enacted in many different ways, and all the pertinent manners of interaction must be at some point integrated. Since every particular representation is always perspectival, we need, to paraphrase Robert Brandom, have many prototypes in order to have any (1994: 89).

\section{Layers of the Frame of Reference}

The space between any given center and periphery can be divided into many different layers, two of which are germane to our considerations (Figure 3).

Level I can be referred to as ideational. It comprises image schemas in the sense of Lakoff and Johnson (1999) and underlies concrete imagery, imagination, and metaphorization. From a human perspective, Level I is prelinguistic but not nonlinguistic. The idea is, rather, that at this level, linguistic content is closely linked with bodily experiences and visual and proprioceptive imagery. In other words, this level has evocative power. The key feature of representations pertaining to this level is overdetermination: the same content can be expressed by different means, and, conversely, a certain means of expression can convey different contents (cf. Merrell, 1997).

Level II is referred to as conceptual-linguistic level to emphasize the fact that it is a domain of activity where we are trying to get rid of ambiguity in the name of objectivity and expand our horizons in a systematic, sometimes almost algorithmic, manner. It comprises the kind of representations that can be expressed by means of rules-based symbolic representations (written language, graphs, equations, and designs). These representations require external memory storages, which in turn make this form of knowledge transmittable. Representations pertaining to Level II include categorical systems used for naming (denoting), conceptual frameworks with strict rules of inference and correspondence, as well as all kinds of bureaucratic institutions. 


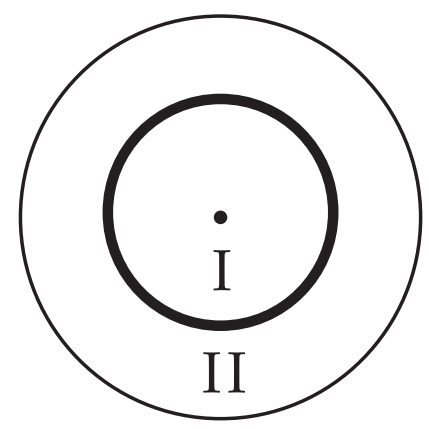

Fig. 3. Ideational (I) and conceptual-linguistic (II) levels.

Level II representations are the most abstract and material (solid) at the same time. They are abstract in the sense of being quite removed from direct engagements and are material in the sense of being more dependent upon specific media of communication and interaction. As we shall see below, this form of objectification simultaneously creates opportunities and poses challenges. In this scheme, abduction, understood as a creative - if regulated - gap filling, is that which connects Levels I and II.

\section{The Function of Cognitive Distancing}

By way of thought experiment, we may ask the following question: why is the movement along circumference spiral? In other words, if we are most at home at the center, why cannot we simply stay as close to the center as possible?

The most straightforward answer to this question has already been provided: finite, empirical creatures that we are, reality can only be served one bit at a time. Note also that the above proposal yields a paradoxical result: what Merlin Donald refers to as episodic culture would be deemed most advanced (Donald, 1991). In other words, we could be tempted to state that episodic culture enables its members to cover all the relevant angles while providing the most direct kind of experience (Figure 4). But it is clearly not so. By way of a short exposition, the concept of episodic culture is based on the fact that mammals are capable of perceiving subtle variations in situational gestalts, but their ability to link and recombine particular gestalts is very limited; they lack metareference and their lives are confined to episodes. With the advent of mimetic culture, we became able to re-present events and mental states, ideally with an evocation of associated experience. Language, in turn, enabled us to produce and communicate stories (mythic culture) and, eventually, to create theoretical and technological systems, subordinated to the principle of replicability (theoretic culture).

Put another way, all living creatures are dynamical systems within larger dynamical systems (ecological niches, lifeworlds, and so on) and constantly interact and 


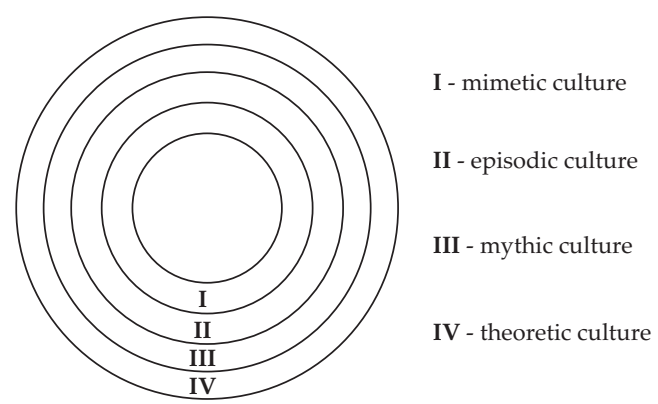

Fig. 4. Donald's categorization of cognitive culture projected against the general frame of reference.

exchange energy and information with these systems. This process amounts to a persistent interference, whose source is twofold: (1) other systems and objects in our vicinity, and (2) our own motivational systems, which tend to compete with one another. The inevitable interferences can discourage exploration by causing repulsion and subsequent aggression or withdrawal. Attraction posed by the possibility of immediate reward is another possible obstacle to exploration, causing consummation to dominate appetites (Panksepp, 1998; Gray \& McNaughton, 2000).

What this means is that although, from a mathematical point of view, every circumference is an ideal curve, since in reality we are always to some extent out of focus, the real circumference is never fully concentric. The shape of real circles is more reminiscent of ink blotches: sometimes we are closer to a center, at other times to a periphery. The overall shape and scope of the whole structure depends on available mechanisms for dealing with resistance and attraction. Put another way, the path around the center always deviates from an ideal curve, where the deviations reflect our current understanding of the situation at hand, our capacities to deal with it, as well as our goals, hopes, and fears associated with it.

As a rule, the less cognitively advanced a system is, the less it is able to deal with inevitable interruptions. It hence makes perfect sense for those less-cognitively sophisticated creatures to compartmentalize their worlds into episodes and associated action blueprints that can be activated swiftly and executed without forethought.

Cognitive advancements, especially at Level II, enable us to turn raw facts (veto power of the world: Habermas, 2003) into scientific facts, in the form of relatively isolated systems (Poincaré, 1952; Duhem, 1962; Cartwright, 1983; Hacking, 1983) with which we can manipulate at will.

\section{Distortions and Biases}

This provokes a reverse question: why cannot we, humans, having achieved a proper level of cognitive advancement, simply move along the outermost circle, 
which is pretty much what Robert Brandom (1994) and other conceptualists recommend? After all, cognitive advancement brings with it ever greater power of exteriorization, which increases in the following order: gestures, spoken language, written language, print, computer technology. What this appears to mean is that owing to conceptual, transmittable knowledge, we are able to overcome the gravitational pull of any center.

The problem is that as far as the frame of reference is concerned, the center is as important as the circumference. Simply put, there is no reference without a center; as shown above, whenever we lose connection with it, our thoughts and actions become essentially meaningless (nonreferential).

As long as we are alive, we remain somehow connected to the center. This means, however, that when moving along any circumference, our actions at every level are skewed by our cognitive makeup and preconceptions. The first problem with the idea that by means of conceptual norms, we can permanently lift ourselves above the much-obscure ideational level is that personal bias, which informs our habits, skews the trajectory of our every movement, movements in conceptual spaces included. These deviations, after reaching a certain threshold of accumulation, can simply derail us. ${ }^{2}$ This applies both to a situation when a person has secondhand knowledge of something, based on which he/she makes inferences and takes decisions, and to his/her personal habits. Once we have traversed a certain space and learned something as a result, certain heuristics have been created, but if we do not bother revisiting, every now and then, the areas upon which these heuristics bear, we are asking for trouble in the long run. In other words, our arguments are steeped in heuristics that we may not be aware of.

Another problem that we encounter in this context is that at Level II, a different type of interference comes into operation. Two or more centers tend to connect wherever there is an overlap between them in terms of either their problematic or conceptual structure (Figure 5). ${ }^{3}$ This generates the risk of going off on tangents. The concept of gravity, for instance, intersects with the problematic of electromagnetism in that both belong to the category of physical forces. Clearly, however, not all concepts and equations used in the former can be applied to the latter, and vice versa.

Essentially, every point of contact between two systems creates opportunity for, or even exchange of forces. Since, however, every two adjacent forces interfere with one another, the point of contact becomes automatically an area of potential mutual contamination: ideas and models (e.g., mathematical equations)

\footnotetext{
2 Note that this was Kuhn's explanation of the inevitable disintegration of scientific paradigms (Kuhn, 1996, $4-5,65)$.

3 Remember that, in fact, every point at the circumference is a point of contact with another system.
} 


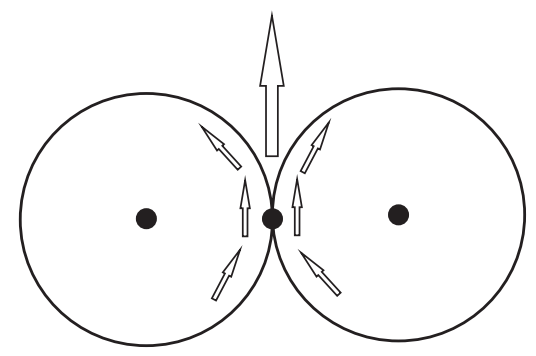

Fig. 5. The dynamics of interaction between different centers.

belonging to one center can influence our reasoning in another domain and potentially lead us astray. ${ }^{4}$ This gives rise to the conceptual fuzziness that other theorists mentioned.

What this analysis entails is that formally valid deductive inference can be contaminated from above, by conceptual rules pertinent to a different system, and affected from below by tacit ideas and working models. ${ }^{5}$ Associated fallacies can be avoided and corrected only if we are committed to moving back and forth between the center and the circumference, in addition to scrutinizing abductive processes through which habits have been created. This can be explained by means of a metaphor: when looking up to the sky from a certain position on earth, certain patterns unfold before our eyes. We can either take these for granted, without much trying to play with the perspective from which we approach them, or attempt to shift the focus every so often as well as to examine the very place from which we observe them.

\section{Shifts of Perspective and the Problem of Coordination}

According to Arnheim's (1988) framework, when a system comes into contact with other systems, there is an increase of both centrifugal and centripetal forces operative in each of them. Such can either lead to a productive exchange or mobilize defenses. What does it, then, mean for a contact between two centers to be productive? In other words, how can uncoordinated semantic shifts be prevented? Imagine a straight line being drawn upward from the point of intersection of two gestalts as shown in Figure 5. When we project the circumferences of both systems involved in the interaction against this line, we get a point from which the interaction can be regulated. Imagine further that this point also casts rays all around it, and thus generates its own ideational and conceptual circumferences. What we have in front of us now is a higher-order gestalt, which not only spans

\footnotetext{
4 Remember that the contact can take place at any circumference. The same logic hence applies to contacts at the ideational level. The relationships between centers are best represented by means of Venn diagrams.

5 As a rule, personal bias has a lot to say when it comes to which of the concepts will be blended together.
} 
over the two intersecting systems (horizontal trajectory), but in suggesting that some latent systems (objects) are located within its confines, it delineates a space for further exploration (vertical trajectory).

What is essential to understand is that the higher-order point, which is a projection of the intersection between two lower-level objects, represents neither a concept (Level II) nor idea (Level I) but constitutes an object of interaction (frame of reference) in its own right. The point generates a field around it, which is to be filled in by ideational and conceptual structures, but it cannot be reduced to either. What this means is that the new system is a new problem situation. It represents the possibility of an understanding of the interconnection among other systems, whereas actionwise, it signifies the manner in which transitions from one system to another can be coordinated. Such transitions involve assessment (self-assessment included) and planning. They must be grounded in a cognitive structure of those desiring to make these transitions.

Every time two systems intersect, we have a decision to make: we can either resist the pull of the other center, staying within the bounds of the field from which we have commenced, or decide to shift from the current center to another, whereby we either change the topic or engage in the exploration of the very intersection. None of these options is fundamentally better than any other, which is to say that there is not a final instance to judge the appropriateness of such choices. The decisions are context dependent and reflect goals, situational awareness, and the temperament of the agents undergoing or resisting the transitions. For instance, there may be a natural scientist, who has dedicated his whole academic, and possibly also nonacademic, life to the study of the population of brown bear in Alaska. He will consistently refuse to be drawn into other types of considerations unless these have a direct bearing on his bear-related research. Contrast this with a case of a social scientist, whose research combines topics and methodologies of, say, both sociology and history. The researcher will have to be very mindful of the point of intersection between the two domains; otherwise, he/she can easily get sidetracked and fail to satisfy the demands of either field. For a philosopher or psychologist, in turn, the very intersection presents a field to explore.

While all three decisions are perfectly legitimate, it is critical for the agents to be aware of all these options and make decisions most appropriate given the context and their long-term goals. In other words, they must be aware of where centers lie in order to act purposefully. No matter what one decides to do, the decision-making process should result in one's being more aware of what the decision entails and how it affects other sectors and domains. In other words, whether one decides to shift perspective or not, one must make sure one has good reasons for doing so. The least we can expect is that one will be vigilant in terms of the possible long-term consequences and ramifications of one's decisions. 


\section{Progression and Reversion}

We can summarize the above analyses using Charles S. Peirce's categorical system (Peirce, 1868; see also Merrell, 1997). According to the Peircean model, semiosis starts with what we may refer to as a primordial situation (Firstness), understood as the process of the emergence of gestalts out of initial chaos. We find ourselves in a primordial situation whenever we allow ourselves to see things differently. In other words, Firstness can be defined as a fluid interplay between that which is known, explicit, and immediately present, and that which is unknown, implicit, and merely possible, but fundamentally discoverable. Depending on the degree to which one is able to bear with this kind of ambiguity, a cognitive "cut" is more or less automatically effected, which leads to a reduction of the initial overdetermination and delineation of relatively clear and distinct natural kinds and separable episodes (Secondness). This enables us to hypothetically order phenomena into sequences of causally linked units and form expectations and hypotheses as to the future courses of events (Thirdness). What must be born in mind during the whole process, however, is that every gestalt has an unlimited number of tacit dimensions that constitute continua, and that object determination is driven by inevitable, tacit biases in the form of cognitive-emotional-behavioral schemas (Alford \& Beck, 1997), image schemas, and acquired procedural and conceptual knowledge. That is to say that every determination is to some degree arbitrary and incomplete (underdetermined). What can hence be expected is that experience will sooner or later undermine our neat categorizations by confronting us with novelty and resistance. Whenever unexpected occurrences and novel items insert themselves, so to say, into our categorical systems and hypothetical sequences, we become motivated to examine them by repeating the above procedure, but at a different level and along a different trajectory. This would generate infinite regress and result in an uncontrollable chase after the unattainable were it not for the possibility for regression to counterbalance progression. ${ }^{6}$ In practical terms, this means that an inquirer should every so often return to the original situation to coordinate the process of inquiry.

Of course, since by then, a profound cognitive transformation has taken place at the level of Firstness, whose many tacit dimensions will have now become explicit (Polanyi, 1962), we will not be dealing with the same gestalt. Nonetheless, the concept of cognitive transformation does not entail that one undergoes a total reset in the process of inquiry and is forced to start from scratch every time. We may say that our transformed gestalt will be "fresh" rather than new in an absolute sense of being entirely unrelated to the initial situation. Once again, it

\footnotetext{
6 The dialectic of progression and regression played a critical part in Neoplatonic philosophy, see, e.g., Klitenic Wear \& Dillon, 2007.
} 
will manifest itself as a combination of the known and the unknown. If we manage to restrain ourselves from taking the cognitive-perceptual transformation for granted, we will be in a position to reexamine it from a renewed standpoint and, thereby, to delineate new trajectories of possible engagement, as well as try to understand which of the abstractive fallacies committed in the process of determination was/were the reason/reasons behind the resistance experienced by us and which consequently require correction.

\section{Conclusions}

The general conclusion from the above analysis is that meaning is created and sustained at the cross section of two kinds of axes, which complement and restrict each other. The delineated model connects the two meanings of intersubjectivity and adds selfhood, or subjectivity, to the equation. In other words, the model shows how intersubjectivity dovetails with, and is inseparable from, subjectivity and objectivity.

The movement along a circumference encircling a given center allows one to appreciate different standpoints from which a given subject matter can be approached and, thereby, to continually eliminate biases. This circular movement represents the ability to situate our own goals and agendas in the context of those of other people's and mutually coordinate actions (Stone, 2011). The second axis that connects the center with the circumference, produces "necessary distance", and can be roughly associated with left-hemispheric activity (McGilchrist, 2010). Its primary role is to help us in untangling incoherent bundles of images, ideas, and motivational forces (or complexes), creating spaces for creative elaboration and mindful enactment. Objectifying distancing enables us to see the larger picture, discern, and assess possibilities occluded by emotional engagement, while habits and norms established in the process confer relative stability and permanence to our understandings and actions. The core idea, however, is that once we have climbed up the cognitive ladder, we need to find a means of returning to the source, wherefrom a renewed sense of purpose may be drawn and used to fuel further interaction and exploration. Since meaningfulness requires that every now and then we reactivate and reinvigorate the center, which has motivated our explorative efforts and represents the purpose behind it throughout the process, as well as its reference, which can only be done through a first-person experience, subjectivity is also a critical ingredient of intersubjectivity and objectivity and hence cannot be eliminated.

\section{Summary}

In the methodology of science, intersubjectivity is usually associated with replicability of experimental results. A related, judicial conception of objectivity as impartiality has it that a theory or judgment is objective if it covers all the relevant angles of the object 
or phenomenon in question, ensuring that the latter is not ephemeral and the concepts referring to them are valid. Based on the assumption that in the social sciences, the researcher is also a participant, an alternative view was conceived, according to the notion that intersubjectivity rests on either sharing of a lifeworld and its associated practices or on empathy, or on some form of direct social cognition.

My aim in this paper is to bring some elements of the Gestalt theory - and more specifically, Rudolf Arnheim's (1988) adapted model of field dynamics - to bear on the problematic of intersubjectivity. The proposed model suggests that intersubjectivity is a dynamic phenomenon, best described as a product of two vectors: a vector describing a movement across the circumference combined with a vector describing the movement from the center to the circumference. While the first vector corresponds to impartiality, the second represents the tension between cognitive distancing and direct experience. Overall, it is argued that intersubjectivity cannot be divorced from either subjectivity or objectivity and it amounts to skillful navigation within different frames of reference.

Keywords: Intersubjectivity, objectivity, cognitive distancing, direct experience, Gestalt theory.

\section{Vom Selbst zum Anderen und Zurück: Intersubjektivität als ständige Bewegung um das Selbst}

\section{Zusammenfassung}

In der wissenschafltichen Methodologie wird Intersubjektivität üblicherweise mit der Austauschbarkeit experimenteller Resultate assoziiert. Eine ähnliche Rechtsauffassung von Objektivität als Unparteilichkeit beinhaltet, dass eine Theorie oder ein Urteil dann objektiv ist, wenn es alle relevanten Perspektiven des fraglichen Objekts oder Phänomens abdeckt und darüber hinaus sicherstellt, dass letzteres nicht ephemer und die Konzepte, auf die es sich bezieht, valide sind. Auf Grund der Annahme, dass in den Sozialwissenschaften der Forscher auch ein Beteiligter ist, wurde eine alternativer Blickwinkel entwickelt, der darauf gründet, dass Intersubjektivität entweder auf einer geteilten Lebenswelt beruht, oder auf geteilten Praktiken, oder auf Empathie, oder irgendeiner anderen Form direkter sozialer Kognition.

Ziel meines Beitrags ist es, einige Elemente der Gestalttheorie - insbesondere Rudolf Arnheims adaptiertes Modell der Felddynamiken - auf die Problematik der Intersubjektivität zu beziehen. Das vorgeschlagene Modell führt dazu, Intersubjektivität als ein dynamisches Phänomen zu betrachten, das am besten als Produkt von zwei Vektoren beschrieben werden kann: der eine Vektor stellt eine Bewegung durch die Peripherie dar, kombiniert mit einem anderen Vektor, der die Bewegung vom Zentrum zur Peripherie darstellt. Während der erste Vektor der Überparteilichkeit entspricht, repräsentiert der zweite Vektor die Spannung zwischen kognitiver Distanzierung und direkter Erfahrung. Zusammenfassend wird argumentiert, dass Intersubjektivität weder von Subjektivität noch von Objektivität losgelöst werden kann, und auf eine kundige Steuerung innerhalb von Bezugssystemen hinausläuft.

Schlüsselwörter: Intersubjektivität, Objektivität, kognitive Distanzierung, direkte Erfahrung, Gestalttheorie. 


\section{References}

Alford, B. A., \& Beck, A. A. (1997). Integrative power of cognitive therapy. London, New York: Guilford Press.

Apel, K. O. (1984). Understanding and explanation. Translated by Georgia Warnke. Cambridge, MA, London: The MIT Press.

Apel, K. O. (1998). Towards a transformation of philosophy. G. Adey \& D. Fisbey (Eds.). Milwaukee, WI: Marquette University Press.

Arnheim, R. (1971). Entropy and art: Essay on disorder and order. Berkeley and Los Angeles: University of California Press.

Brandom, R. B. (1994). Making it explicit: Reasoning, representing, and discursive commitment. Cambridge, MA: Harvard University Press.

Cartwright, N. (1983). How the laws of physics lie. Oxford, UK: Clarendon Press.

Donald, M. (1991). The origins of the modern mind: Three stages of the evolution of culture and cognition. Cambridge, MA, London: Harvard University Press.

Dray, W. (1957). Laws and explanation in history. Oxford, UK: Oxford University Press.

Duhem, P. (1962). The aim and structure of physical theory. Translated by Philip P. Wiener. New York, NY: Atheneum.

Fordham, M. (1976). The self and autism, volume III of library of analytical psychology. London, UK: Academic Press.

Fordham, M. (1981). Neumann and childhood. Journal of Analytical Psychology, 26(2), 99-122.

Gallagher, S. (2008). Direct perception in the intersubjective context. Consciousness and Cognition, 17(2), 535-543. doi: 10.1016/j.concog.2008.03.003.

Gallagher, S., \& Zahavi, D. (2008). The phenomenological mind. London, NY: Routledge.

Gallese, V. (2003, July-August). The roots of empathy: The shared manifold hypothesis and the neural basis of intersubjectivity. Psychopathology, 36(4), 171-180. doi: 10.1159/000072786.

Gallese, V. (2005, March). Embodied simulation: From neurons to phenomenal experience. Phenomenology and the Cognitive Sciences, 4(1), 24-48. doi: 10.1007/s11097-005-4737-z.

Gardenförs, P. (2004) Conceptual spaces: The geometry of thought. Cambridge, MA: MIT Press/A Bradford Book.

Gray, J., \& McNaughton, N. (2000). The neuropsychology of anxiety: An enquiry into the function of the Septo-Hippocampal System. Oxford, UK: Oxford University Press.

Habermas, J. (2003). Truth and justification. Translated by Barbara Fultner. Cambridge, MA: MIT University Press.

Hacking, I. (1983). Representing and intervening. Cambridge, MA: Cambridge University Press.

Klein, M. (1986). Notes of some Schizoid mechanisms. In J. Mitchell (Eds.), The selected Melanie Klein (pp. 175-200). New York, NY: The FreePress.

Klitenic Wear, S., \& Dillon, J. (2007). Dionysius the areopagite and the neoplatonist tradition: Despoiling the Hellenes. Aldershot, England: Ashgate Publishing Limited.

Kögler, H. H., \& Stueber, K. R. (Eds.) (2000). Empathy and agency: The problem of understanding in the human sciences. Boulder, Oxford: Westview Press.

Kuhn, T. S. (1996). The structure of scientific revolutions. Chicago, IL: The University of Chicago Press.

Lakoff, G., \& Johnson, M. (1999). Philosophy in the flesh: The embodied mind and its challenge to the Western thought. New York, NY: Basic Books.

Landesmann, Ch. (1965, December). The new Dualism in the philosophy of mind. Review of Metaphysics, 19(2), 329-345.

Lipps, T. (1979). Empathy, inner imitation, and sense-feelings. In M. Rader (Ed.), A modern book of esthetics (4th edn, pp, 374-382). New York, NY: Holt, Rinehart, and Winston.

Lyotard, J.-F. (2011). Discourse, figure. Translated by Antony Hudek, and Mary Lydon. Minneapolis, London: University of Minnesota Press.

McGilchrist, I. (2010). The master and his emissary: The divided brain and the making of the western world. New Haven, CT: Yale University Press.

Merrell, L. (1997). Peirce, signs, and meaning. Toronto, Buffalo, London: University of Toronto Press.

Neumann, E. (1963). The origins and history of consciousness; The great mother: An analysis of the archetype, Translated by Ralph Manheim. New York, NY: Bollingen Foundation.

Panksepp, J. (1998). Affective neuroscience: The foundations of human and animal emotions. New York \& Oxford: Oxford University Press.

Peirce, Ch. S. (1868). On a new list of categories. Proceedings of the American Academy of Arts and Sciences, 287-298. 
Poincaré, H. (1952). Science and hypothesis. New York, NY: Dover Publications.

Polanyi, M. (1962). Personal knowledge: Towards post-critical philosophy. London, UK: Routledge.

Popper, K. R. (2002). Logic of scientific discovery. London, New York: Routledge.

Quine, W. V. O. (1953). Two dogmas of empiricism. In From a logical point of view (pp. 20-46). Cambridge,

MA: Harvard University Press.

Scheler, M. (1954). The nature of sympathy. London, UK: Routledge and Kegan Paul.

Stone, D. A. (2011, June). The experience of the tacit in multi- and interdisciplinary. Phenomenology and Cognitive Sciences, 12(2), 289-308. doi: 10.1007/s11097-011-9248-5.

Von Wright, G. H. (1971). Explanation and understanding. Ithaca, NY: Cornell University Press.

Winch, P. (2003). The idea of a social science and its relation to philosophy, 2nd ed. London, UK: Routledge.

Wittgenstein, L. (1922). Tractatus logico-philosophicus. Translated by C. K. Ogden. London, UK: Kegan Paul, Trench, Trübner\& Co. Ltd., Hew York: Harcourt, Brace, and Company.

Anna Michalska, born in 1981, is Assistant Professor of Philosophy at the Institute of Philosophy and Sociology of the Polish Academy of Sciences. Central points of her research are social philosophy, transcendental pragmatics, and philosophy of science. Main publications: Gestalt and Science. Kuhn's Model of Scientific Change in the Light of Gestalt Theory, Filozofia i Nauka, 2015; What Brandom Won't Make Explicit. On Habermas's Critique of Brandom, Philosophy \& Social Criticism, 2018; Norms, Facts, Ideals: Idealization and Self-regulation in Human Interactions, Wydawnictwo IFiS PAN, Warszawa, 2019; Does Philosophy Require De-Transcendentalization? Habermas, Apel, and the Role of Transcendentals in Philosophical Discourse and Social-Scientific Explanation, Acta Universitatis Lodziensis. Folia Philosophica. Ethica-Aesthetica-Practica, 2020.

Address: Institute of Philosophy and Sociology of the Polish Academy of Sciences, Nowy Świat 72, 00-330 Warsaw.

E-mail: amichalska@ifispan.edu.pl

ORCID: 0000-0002-2551-4556 